\title{
In vivo Visualization of the Growth of Pre- and Postsynaptic Elements of Neuromuscular Junctions in the Mouse
}

\author{
Rita J. Balice-Gordon and Jeff W. Lichtman \\ Department of Anatomy and Neurobiology, Washington University School of Medicine, St. Louis, Missouri 63110
}

In order to study how neuromuscular junctions grow, we have repeatedly viewed the same junctions in mouse sternomastoid muscles at monthly intervals from 2 weeks to 18 months of age. Motor nerve terminals were stained with the nontoxic fluorescent dye 4-Di-2-ASP (Magrassi et al., 1987), and postsynaptic $\mathrm{ACh}$ receptors were labeled with fluorescently tagged $\alpha$-bungarotoxin.

Neuromuscular junctions grew primarily by expansion of existing motor nerve terminal and postsynaptic receptor regions without the addition or loss of synaptic areas. The expansion of pre- and postsynaptic specializations was precisely matched, suggesting that as neuromuscular junctions grow, the opposing specializations enlarge simultaneously.

Each neuromuscular junction grew in length and width at the same rate that muscle fibers enlarged in those 2 dimensions, suggesting that junctional growth might be a mechanical consequence of muscle fiber growth. Repeated visualization of ACh receptors over time showed that previously labeled receptors spread apart in the membrane occupying a progressively larger area as muscle fibers grew. At the same time, new receptors were intercalated throughout the enlarged postsynaptic area. Thus, the growth of postsynaptic regions appears to be directly related to the expansion of the muscle fiber membrane as muscle fibers grow. The maintained alignment between growing motor nerve terminals and postsynaptic regions suggests that nerve terminal growth may be a consequence of its adhesion to growing postsynaptic specializations. This conclusion is supported by the coextensive stretching of motor nerve terminals and postsynaptic regions when muscle fibers are stretched. Thus, the growth of motor nerve terminals is coupled to the growth of postsynaptic regions, and the growth of the postsynaptic regions is in turn coupled to the growth of muscle fibers. In this way, the branching pattern of neuromuscular junctions may be stably maintained despite ongoing enlargement of synaptic area.

It has long been appreciated that there is an impressive correlation between the size of target cells and the strength of the synapses that innervate them. In muscle, this "size matching"

Received Aug. 29, 1989; revised Oct. 12, 1989; accepted Oct. 18, 1989.

We thank Christine Chua for her help with morphometric analysis, Sherman Owens for technical assistance, and Drs. I. Cohen, D. Falls, D. Purves, G. Reiness, M. Rich, J. Sanes, and P. van Mier for helpful discussions and comments. Supported by grants from the NIH and MDA to J.W.L. and the Harry Zimmerman Postdoctoral Fellowship of the MDA to R.B.G.

Correspondence should be addressed to Rita J. Balice-Gordon, Department of Anatomy and Neurobiology, Washington University School of Medicine, $660 \mathrm{~S}$. Euclid, Box 8108, St. Louis, MO 63110.

Copyright (c) 1990 Society for Neuroscience $0270-6474 / 90 / 030894-15 \$ 02.00 / 0$ is apparent when the amount of neurotransmitter released at a neuromuscular junction is compared with the size of the muscle fiber: large muscle fibers have synapses that release more neurotransmitter than junctions on small muscle fibers. Furthermore, as animals grow, muscle fibers increase in size and there is a compensatory increase in the amount of neurotransmitter released at neuromuscular junctions (Kuno et al., 1971; Bennett and Raftos, 1977; Harris and Ribchester, 1979; Nudell and Grinnell, 1983; Wernig and Herrera, 1986).

The physiological relation between transmitter release and muscle fiber size has a structural analog: the physical size of neuromuscular junctions correlates both with the amount of transmitter released and with the size of muscle fibers. Thus, at any one age, large muscle fibers have larger synapses than small muscle fibers. Moreover, as muscle fibers enlarge, their synapses get progressively larger (Nyström, 1968; Teräväinen, 1968; Kuno et al., 1971; Bennett and Raftos, 1977; Kelly, 1978; Brown et al., 1981; Steinbach, 1981; Slater, 1982; Slack et al., 1983; Hopkins et al., 1985; Lichtman et al., 1987; Ogata, 1989).

How functional and structural size matching are accomplished is not well understood. In some muscles, dynamic studies of motor nerve terminals in living animals have suggested that the size and branching pattern of individual neuromuscular junctions may be altered by the continual addition and retraction of branches (Robbins, 1988; Herrera et al., 1990; Wigston, 1989). However, it is uncertain how this plasticity is related to the overall growth of neuromuscular junctions.

In one study, size changes at neuromuscular junctions in adult animals past the ages of rapid growth were accounted for primarily by growth of existing motor nerve terminal branches (Lichtman et al., 1987). In the present work, we pursue this matter further by addressing several questions. First, how do junctions grow between 2 weeks and 3-4 months of age when synaptic area may increase 4-fold or more (Hopkins et al., 1985)? Does growth occur at the cnds of motor nerve terminal branches, as sprouts off of existing branches, or in some other fashion? Second, how do the postsynaptic ACh receptor areas enlarge? Do motor nerve terminals sprout into new areas followed by insertion or migration of $\mathrm{ACh}$ receptors or vice versa, or is preand postsynaptic growth concurrent? Finally, we wished to determine what sorts of mechanisms might underlie the enlargement of synaptic area that occurs in growing animals. We have addressed these questions directly by viewing the same neuromuscular junctions repeatedly over many months.

\section{Materials and Methods}

Fourteen- to 21 -d-old mice (CF1 B strain, Harlan/Sprague-Dawley, Inc.; or C57B1 6J strain, Jackson Laboratories) were obtained from in-house breeding colonies. To decrease the variability in size and weight of pups in large litters, litters were culled to 6 when pups were $4 \mathrm{~d}$ old. Sex 
determined after 2-3 weeks of age revealed that $48 \%$ of mice used were male. On average, mice weighed $5-7 \mathrm{gm}$ at 2 weeks of age; $13-15 \mathrm{gm}$ at 1 month; $24-30 \mathrm{gm}$ at 3 months; and $32-46 \mathrm{gm}$ at 12 months.

Visualization of motor nerve terminals and ACh receptors. Mice were anesthetized with choral hydrate $(0.6 \mathrm{gm} / \mathrm{kg}$, i.p.) and weighed, and nose-to-rump length was measured. The animals were mechanically respirated and the left sternomastoid muscle exposed as described in Lichtman et al. (1987). Motor nerve terminals were stained with 4-Di2-ASP (Molecular Probes, Inc., Eugene, OR; Lichtman et al., 1987). The postsynaptic distribution of ACh receptors was stained with rhodamine-conjugated $\alpha$-bungarotoxin so that synaptic transmission was not affected (Rich and Lichtman, 1989a).

Neuromuscular synapses were visualized using conventional epifluorescence optics and video microscopy (Lichtman et al., 1987; Rich and Lichtman, 1989a). After recording the general arrangement of neuromuscular junctions using a $25 \times$ water-immersion objective (Leitz NPL Fluotar; 0.6 numerical aperture), the motor nerve terminal arbors or postsynaptic $\mathrm{ACh}$ receptors of interest were viewed on a video monitor using 50 and $100 \times$ water-immersion objectives (Leitz NPL Fluotar, numerical apertures 1.0 and 1.2 , respectively). The metal casing of the $100 \times$ objective was machined down to fit into the neck of young mouse pups. Video images were digitized, averaged (32 or 64 images) and stored on optical disks using the IMAGR language created by J. Voyvodic, with programs written by W. Sunderland and L. Hedayati. Once images of the selected neuromuscular synapses were obtained, the wound was closed with sutures and the animals warmed under a heat lamp until fully recovered from the anesthesia, when they were returned to their litter. The stored images were photographed on $35 \mathrm{~mm}$ slide film or on a videoprinter (Sony) after digital contrast enhancement.

In somc cxpcriments, both motor nerve terminals and ACh receptors were studied; in these animals, rhodamine-conjugated $\alpha$-bungarotoxin was first applied and ACh receptors photographed. 4-Di-2-ASP was then applied and motor nerve terminals photographed. Because 4-Di2-ASP staining "bleeds" through the fluorescence filters for rhodamine, the $\mathrm{ACh}$ receptors were subsequently rephotographed and the resulting image, consisting of receptor and the bleed-through nerve terminal staining, was used to correctly align the initial $\mathrm{ACh}$ receptor image with the motor nerve terminal image obtained with filters for fluorescein.

Conjugation of AMCA to $\alpha$-bungarotoxin. AMCA (7-amino-4-methylcoumarin-3-acetic acid, succinimidyl ester; Molecular Probes, Eugene, OR; Khalfan et al., 1986) conjugated $\alpha$-bungarotoxin was prepared using the general procedure of Ravdin and Axelrod (1977) with the following modifications. AMCA was dissolved in dry DMSO $(10 \mathrm{mg} / \mathrm{ml})$ and 10 $\mu \mathrm{l}$ was added to $1 \mathrm{ml} \alpha$-bungarotoxin (Biotoxins, Inc.) dissolved ( $2 \mathrm{mg}$ ' $\mathrm{ml})$ in phosphate buffer $(100 \mathrm{~mm}, \mathrm{pH} 8.5)$. The reaction mixture was gently stirred at room temperature for $1 \mathrm{hr}$. The mixture was placed on a P6 10DG column (BioRad; $1.5 \times 8 \mathrm{~cm}$ ) and eluted with $5 \mathrm{~mm}$ phosphate buffer, pH 7.4 (running buffer). The fluorescent peak was placed on a CM-Sephadex C-50 (Sigma) cation-exchange column $(1 \times 25 \mathrm{~cm})$ previously equilibrated with running buffer. The C-50 column was then eluted with $20 \mathrm{ml}$ of running buffer, followed by a $50 \mathrm{ml}$ linear gradient of 0-100 mM sodium chloride in buffer. Aliquots of $1 \mathrm{ml}$ were gathered, and the column was finally eluted with $20 \mathrm{ml}$ of $250 \mathrm{mM} \mathrm{NaCl}$ in running buffer.

To determine where the AMCA-conjugated bungarotoxin was eluted, optical densities (280 $\mathrm{nm}$ for protein) and absorbance spectra $(335 \mathrm{~nm}$ for AMCA) were measured on a Gilford spectrophotometer. $\alpha$-Bungarotoxin conjugated to a single AMCA molecule exhibited the strongest fluorescence and lowest background staining and was eluted as a peak beginning at $40 \mathrm{~mm} \mathrm{NaCl}$. Using various concentrations of BSA (Sigma) to construct a standard curve and optical density measurements (280 $\mathrm{nm}$ ), the concentration of AMCA-conjugated $\alpha$-bungarotoxin in the relevant fractions was determined to be ca. $5 \mu \mathrm{g} / \mathrm{ml}$. BSA was then added to a final concentration of $1 \mathrm{mg} / \mathrm{ml}$. AMCA-conjugated $\alpha$-bungarotoxin was used in the present experiments at a final concentration of $1 \mu \mathrm{g} / \mathrm{ml}$ after dilution with Ringer's (Travenol).

Control procedures. Because of potential phototoxicity of illuminating stained motor nerve terminals and/or untoward effects of labeling ACh receptors with $\alpha$-bungarotoxin, we studied mice $(N=67$ animals; 741 junctions) between 2 weeks and 18 months of age to assess the normal development of neuromuscular junctions. Neuromuscular junctions in this group of animals wcre visualized only once to determine the normal growth (length, width, and area) of neuromuscular synapses. Some of these data are shown in Figures 9 and 10. No differences in neuromuscular junction morphology or size were observed when we compared singly and multiply viewed junctions. Even junctions which had been viewed a dozen times over many months had similar morphologies and sizes to junctions viewed for the first time at comparable ages. Furthermore, similar staining techniques have previously been used to study normal (Lichtman et al., 1987) and reinnervated adult junctions (Rich and Lichtman, 1989a) without obvious disruption.

Another concern is that the procedure used to relocate neuromuscular junctions may be biased in favor of identifying junctions which have remained similar from observation to observation. It is possible that some junctions may have remodeled so extensively between observations that they could not be recognized at the subsequent experiment. Of 522 junctions viewed multiple times, only 7 could not be relocated at a subsequent observation. More often, junctions were rotated on their sides at the next observation, partially obscuring some parts of the junction from view. Although these partially visible synapses $(N=192)$ wcre not analyzed further, in each case, those motor nerve terminal branches or postsynaptic receptor areas which could be compared from view to view grew similarly to other junctions.

\section{Results}

Motor nerve terminals in the sternomastoid muscle grow without addition of new branches

To investigate growth of neuromuscular junctions directly, we repeatedly examined the same motor nerve terminals in living animals from early postnatal life into adulthood. We studied 154 different motor nerve terminals a total of 676 times at monthly intervals in mice ranging in age from 0.5 to 18 months (35 viewed twice; 34 three times; 23 four times; 27 five times; 20 six times; 1 eight times; 7 nine times; 5 twelve times; and 2 thirteen times). Because sternomastoid neuromuscular junctions varied continuously by morphological criteria such as area, length, width, and number of branch ends (complexity), we treat sternomastoid neuromuscular junctions as a single but widely variable group.

Each motor nerve terminal arborization that was examined multiple times during the animals' lifetime grew rapidly from 0.5 to 3-4 months of age and thereafter more slowly. The sternomastoid muscle contains 2 types of junctions which grew in a similar manner: relatively small and compact junctions (Fig. 1) and larger junctions (Fig. $2 A$ ), which were more common in the muscle. There was a roughly 4-fold increase in synaptic area between 2 weeks and 1 year of age. This increase was most rapid (ca. $20 \mu \mathrm{m}^{2} / \mathrm{d}$ ) from 2 weeks to $3-4$ months; after this time, the growth rate of neuromuscular junctions decreased. The increases in area, length, and width of the junctions illustrated in Figures 1 and 2 are plotted in Figure 3. Their growth curves are representative of all of the junctions studied in this fashion.

To determine whether the growth of motor nerve terminals was due to the formation of new branches, we studied the branching pattern of individual junctions over timc (Table 1). If junctions grew by the addition of new branches, then each terminal arbor should have more branches as it enlarges. However, in $70 \%(108 / 154)$ of the nerve terminals followed (each viewed on average 5 times over a 5 month period), no new branches were added because at each of these junctions each branch (stained with 4-Di-2-ASP) present at the last view was also present at each of the previous views. Nonetheless, these nerve terminals had grown considerably, tripling their area over 5 months. Thus, most sternomastoid neuromuscular junctions grow without the addition of new branches.

Although nearly a third of the junctions studied underwent an addition at some point in their life history, these were relatively infrequent and were not progressive. In only $8 \%$ of total junction views (54 of 676) were changes from the previous pat- 


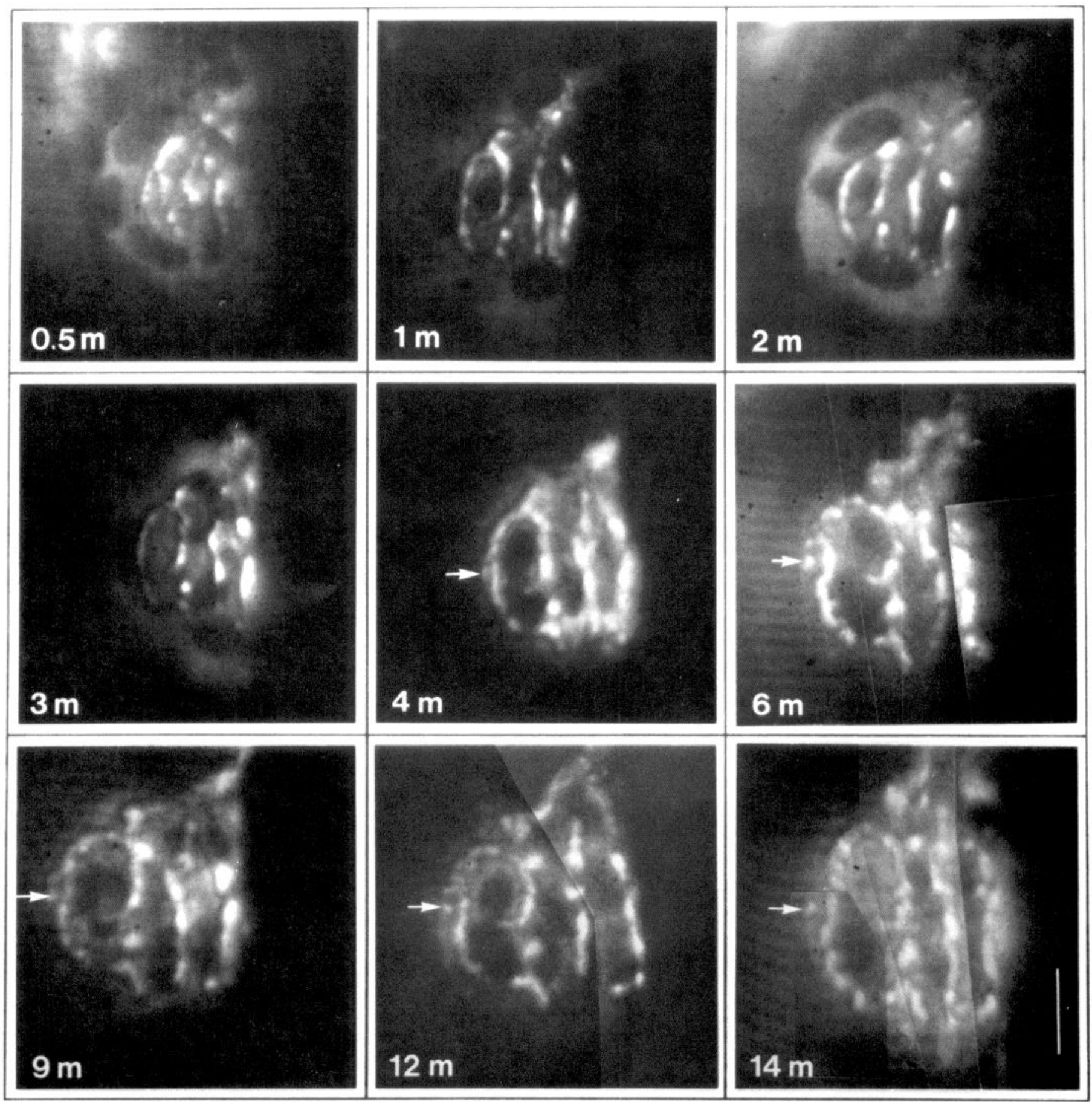

Figure 1. Nine views of a compact neuromuscular junction followed over the first year of life. This motor nerve terminal was stained for the first time with 4-Di-2-ASP in a 2-week-old mouse and was subsequently restained and reviewed 8 times. In this and all subsequent figures, the muscle fibers are oriented vertically. The preterminal axon can be seen at the top of each panel, where it gives rise to the 4 major branches of this neuromuscular junction. Comparison of the junction from view to view shows that the branches elongate, the separation between branches increases, and the angle at some of the branch bifurcations increases over time. The number of myofibrillar striations covered by this neuromuscular junction increases from 8 at 0.5 months to 15 at 14 months, whereas the spacing of the striations remains relatively constant, an indication that the muscle fiber membrane at the junction expands to cover more intracellular constituents. The muscle fiber nuclei, which are seen as dark ovals around and within the junctional region, seem to shift in position from view to view. Arrows indicate a spot of 4-Di-2-ASP staining which was added at 4 months and was subsequently stably maintained. See Figures 3-5 for morphometry of this junction. Scale bar, $20 \mu \mathrm{m}$.

tern observed (average interval between views, 1 month). These additions were typically small ( $<10 \mu \mathrm{m}$ in length) and rarely (6 of 42) was more than one site added per junction over the several month interval studied. Generally, additions occurred along the length of existing branches (see, for example, arrows in Fig. 1).
Once small branches were added, these did not continue to grow at a faster rate than the junction as a whole. These results indicate that the growth of sternomastoid motor nerve terminals does not require the addition of new branches.

In $3 \%$ of the motor nerve terminals studied (4 of 154) at 

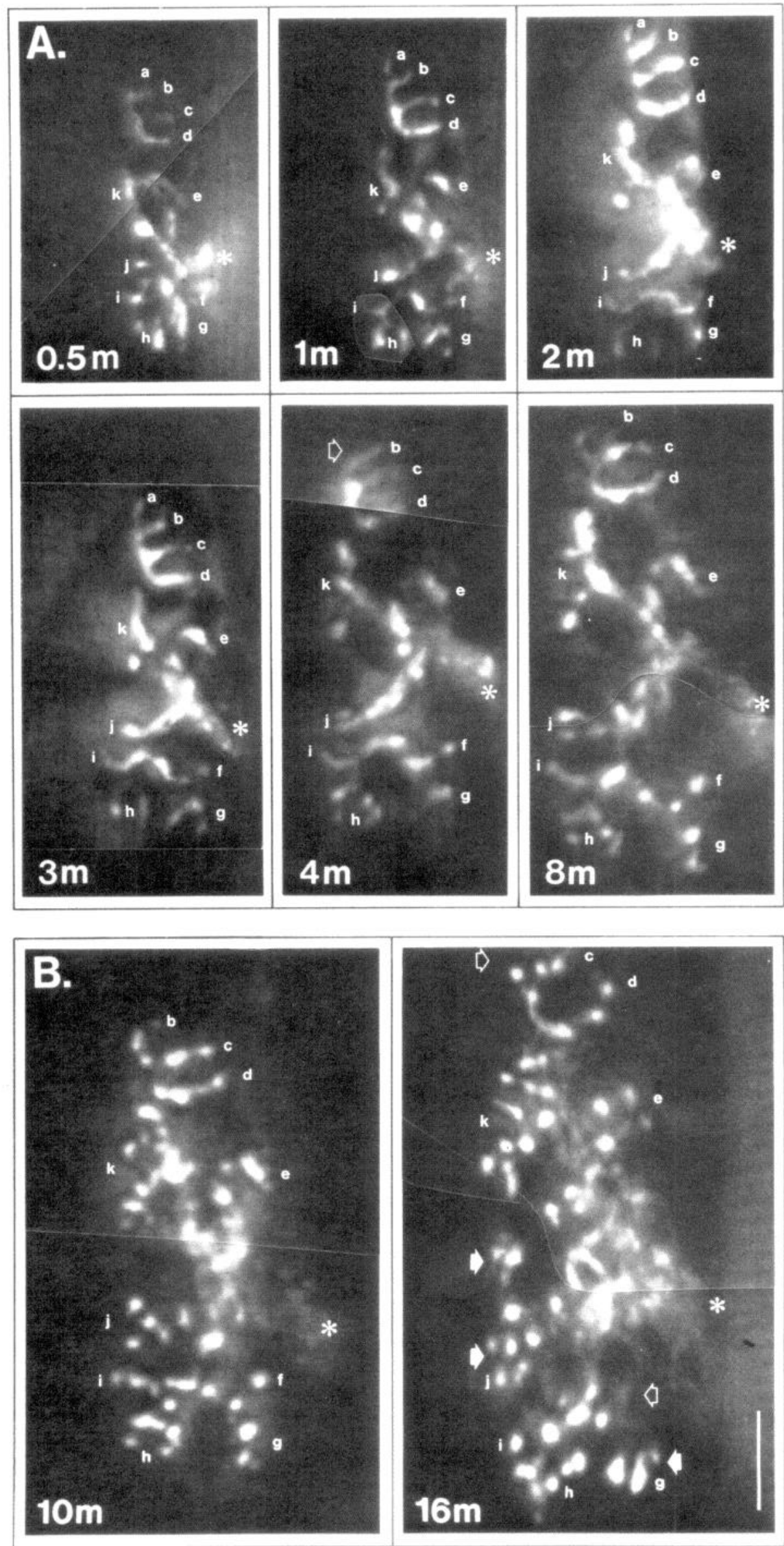

Figure 2. Eight views of an elongated neuromuscular junction followed during the period of rapid postnatal growth to old age. The preterminal axon (asterisk) is seen at the right of each panel, where it enters the midregion of the junction and bifurcates. Lower-case letters indicate the same branches in each view. $A$, Although the junction increases in size significantly, the branching pattern is largely the same from view to view. $B$, As the animal ages (10 months), the motor nerve terminal staining becomes spotty (left panel). At later ages (16 months in right panel), some regions of staining are lost (open arrows), while others are added (closed arrows). Conventional histological techniques show junctions similar in morphology in aged animals (see Robbins, 1988, for review). See Figures 3 and 5 for morphometry of this junction. Scale bar, $20 \mu \mathrm{m}$. 


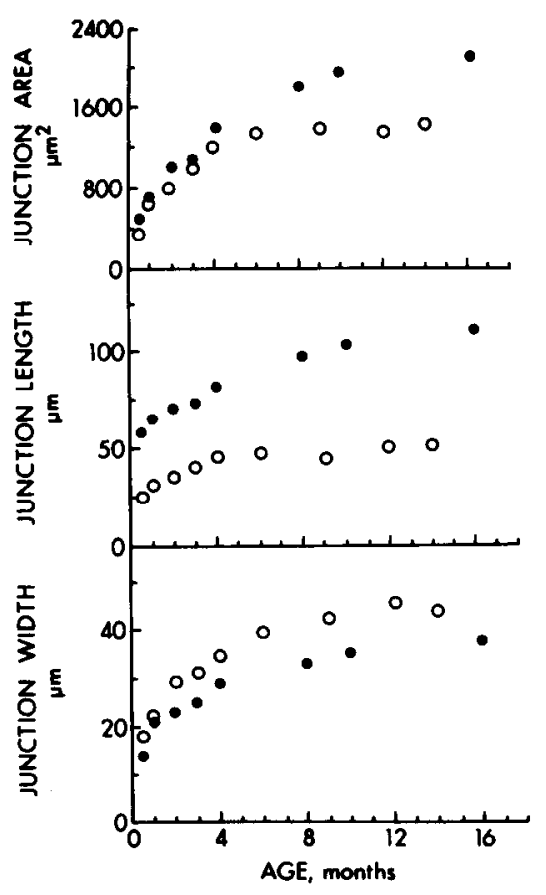

Figure 3. Growth curves of individual junctions followed over time. Growth of the junction shown in Figure 1 (open circles) and the junction shown in Figure 2 (closed circles) are plotted against age. Area, length, and width measured from original data slides projected directly onto a digitizing tablet. These parameters increase rapidly until 3-4 months of age and then more slowly.

multiple times, there were fewer sites of 4-Di-2-ASP staining at the final view. This loss did not appear to be progressive. All of the sites which were lost were $<10 \mu \mathrm{m}$ in length, and in each case no more than 1 or 2 small sites were lost per junction. Junctions which lost sites of 4-Di-2-ASP staining grew to the same extent as junctions that did not (Table 1). Thus, growth of neuromuscular junctions in the sternomastoid muscle is apparently independent of changes in the number of motor nerve terminal branches at each junction. Furthermore, the vast majority of the motor nerve terminal branching pattern is stably maintained over many months with little or no modification.

However, as animals aged ( $>1$ year), we observed more extensive changes at some neuromuscular junctions (Fig. 2B). These alterations included an overall change in the staining pattern (both nerve terminals and receptors became spotty), frequent addition of new sites, and loss of other regions.

\section{Growth occurs by the elongation of existing motor nerve} terminal branches

To better understand how motor nerve terminals enlarged, we measured the length of branches and several other aspects of

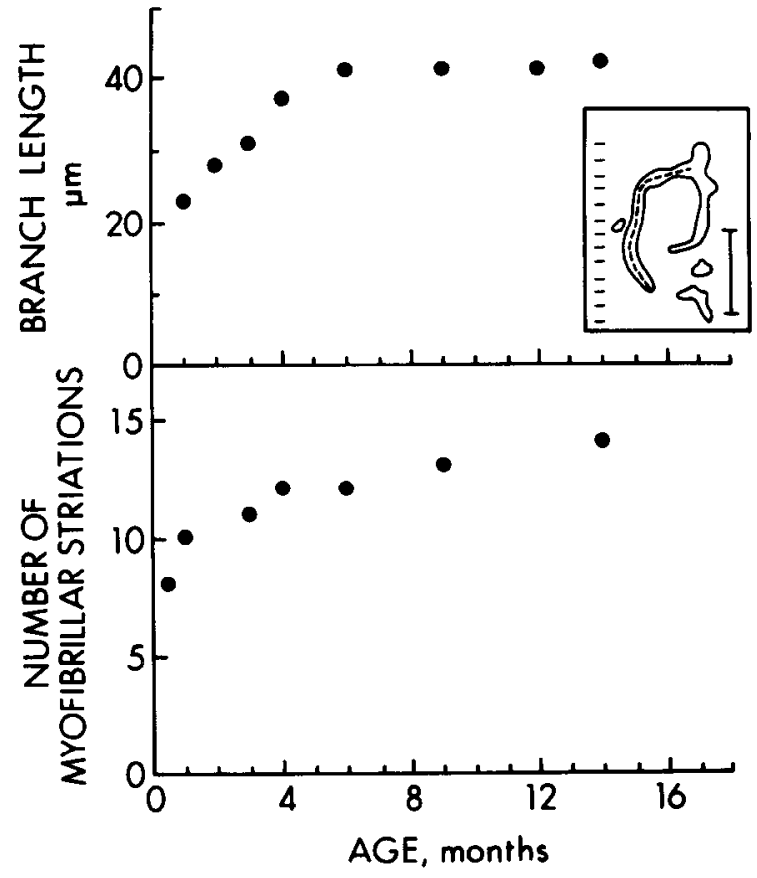

Figure 4. Individual motor nerve terminal branches lengthen as growth occurs. Inset, Camera lucida drawing of the left portion of the 9 month time point of the junction shown in Figure 1. The dashed line indicates the length of the nerve terminal branch measured in each of nine views. Horizontal lines represent the striations in the myofibrils beneath the nerve terminal. Top, Length of the branch as a function of age. Bottom, Number of sarcomeres beneath the nerve terminal as it elongates, plotted against age. As the junction enlarges, it comes to overlie progressively more myofibrillar sarcomeres. Scale bar (in inset), $20 \mu \mathrm{m}$.

junctional structure at multiple times. Virtually every branch at each of the junctions elongated, indicating that this is the principal way motor nerve terminals enlarge (Fig. 4). Enlargement results in the nerve terminal overlying a progressively larger region of the postsynaptic cell as indicated by a gradual increase in the number of myofibrillar striations (sarcomeres) that underlie the synapse (Fig. 4; see also Fig. 1).

In order to determine whether this elongation was caused by preferential growth at the ends of branches or resulted from a more uniform elongation of branches due to intercalary addition of membrane, we measured the length of nerve terminal branches between 2 internal points (e.g., between bifurcations or between bends) to see if they grew more slowly than branch ends (Fig. 5). Repeated views of these internal branch parts showed that intercalary branch lengths increased to the same extent as branches as a whole elongated. For example, the intercalary branch length measured from the E-shaped region in Figure 2 (plotted in Fig. 5, top) increased 1.4-fold (from 9.7 to $13.2 \mu \mathrm{m}$ )

Table 1. Growth of sternomastoid neuromuscular junctions followed over time

\begin{tabular}{|c|c|c|c|c|c|c|c|}
\hline \multirow[b]{2}{*}{ Junctions } & \multirow[b]{2}{*}{$N$} & \multirow[b]{2}{*}{$\%$} & \multicolumn{2}{|l|}{ First view } & \multicolumn{2}{|l|}{ Last view } & \multirow{2}{*}{$\begin{array}{l}\text { Fold } \\
\text { increase } \\
\text { per month }\end{array}$} \\
\hline & & & $\begin{array}{l}\text { Age } \\
\text { (months) }\end{array}$ & Area $\left(\mu \mathrm{m}^{2} \pm \mathrm{SD}\right)$ & $\begin{array}{l}\text { Average age } \\
\text { (months } \pm \text { SD) }\end{array}$ & Area $\left(\mu \mathrm{m}^{2} \pm \mathrm{SD}\right)$ & \\
\hline No change & 108 & 70 & 0.5 & $621 \pm 223$ & $5.4 \pm 0.2$ & $1937 \pm 903$ & 0.6 \\
\hline Branches added & 42 & 27 & 0.5 & $655 \pm 239$ & $4.0 \pm 0.3$ & $1685 \pm 1043$ & 0.6 \\
\hline Branches lost & 4 & 3 & 0.5 & $703 \pm 215$ & $4.8 \pm 0.5$ & $1621 \pm 742$ & 0.5 \\
\hline
\end{tabular}


between 1 to 4 months of age. Similarly, the length of the same branch from end to end increased 1.5-fold over the same interval. Thus, the growth of motor nerve terminals seems to be duc to uniform clongation without any sign of preferential growth at the ends of branches. This point is further supported by the relative constancy of the shape of endplates as they grew. If branches grew at their ends, the branching pattern would become skewed to contain progressively longer segments distal to points of bifurcations. However, at every junction followed, both distal and proximal parts of the branching pattern enlarged in parallel (see, for example, upper E-shaped region of junction shown in Fig. 2).

It was also clear that the growth of nerve terminal branches was matched by a parallel expansion of the area between branches. For example, when we viewed one junction 9 times between 2 weeks and 14 months of age, we found that both the separation between branches in the direction of the long axis of muscle fibers (Fig. 5, middle) and the separation between branches in the direction of the width of muscle fibers (Fig. 5, bottom) increascd with a timc course similar to that of junctional length and width, respectively. This is consistent with the idea that nerve terminal growth occurs in parallel with an overall expansion of the entire area where the nerve terminal resides.

In one respect, however, the change in the shape of nerve terminals was not easily explained by intercalary expansion of all the branches. At many junctions, the angle between branches at bifurcations gradually increased. For example, in Figure 1, the wishbone-shaped bifurcation at the top of the left-most pair of branches gradually increases from approximately $30^{\circ}$ at 0.5 months to $80^{\circ}$ at 3 months to $105^{\circ}$ at 9 months. It is difficult to imagine how motor nerve terminal growth could account for this increase; rather, it appears as if the branches were pulled apart gradually as they enlarged (see below).

We also observed one other change in the 4-Di-2-ASP staining of nerve terminals followed over time: branches that initially were continuously stained gradually became a linear series of discontinuously stained spots (Fig. 6). These spots increased in number as the junctions grew without any alteration in the overall branching pattern. Because 4-Di-2-ASP staining localizes to the compartment of synaptic boutons, which contains mitochondria (Lichtman et al., 1989), this alteration in the staining pattern presumably reflects a change in the intracellular distribution of mitochondria rather than a change in the pattern of nerve terminal branches. As mentioned above, the nerve terminal staining also becomes spotty in old animals ( $>1$ year of age). In distinction to the changes shown in Figure 6, aged junctions add many new branches and also lose synaptic areas (Fig. 2B).

\section{Postsynaptic regions enlarge in parallel with nerve terminals}

Motor nerve terminal growth is accompanied by an increase in the size of the postsynaptic specialization as visualized with fluorescently tagged $\alpha$-bungarotoxin. In every ACh receptor distribution we examined at multiple times $(N=99 ; 21$ viewed twice, 35 three times, 37 four times, and 6 six times), there was overall enlargement (Fig. 7).

As with nerve terminals, receptor regions enlarged by expansion without the addition of new areas of receptors. In 95 of 99 ncuromuscular junctions vicwed multiple timcs over an average interval of 5 months, each of the postsynaptic receptor-rich areas present at the first observation was present at each subsequent observation; conversely, each of the receptor sites present at the

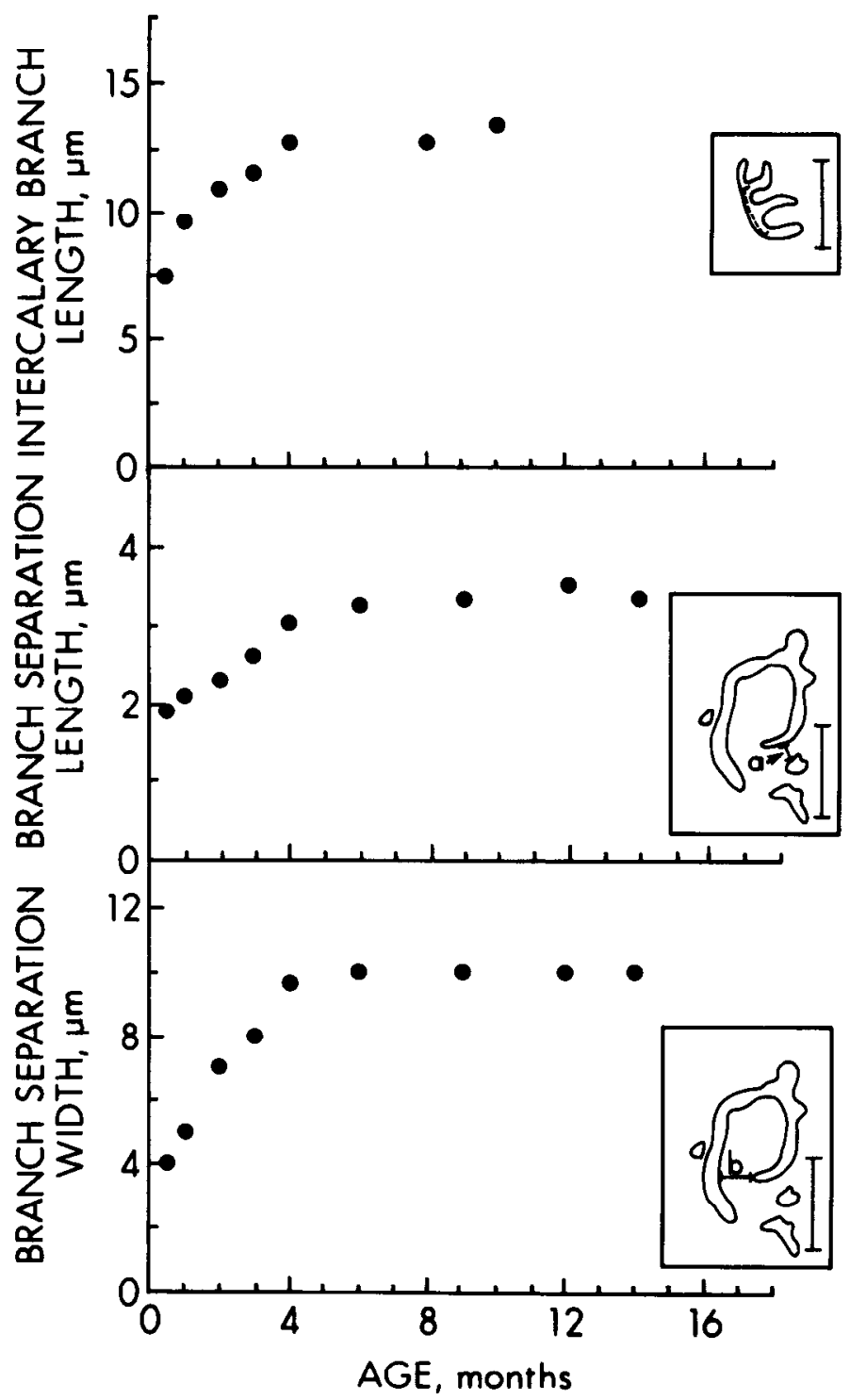

Figure 5. Growth of individual neuromuscular junctions is predominantly intercalary. Top, Inset is a camera lucida tracing of the 2 month time point of a portion of the junction shown in Figure 2 . The distance between a point of bifurcation and an internal bend is indicated with a dashed line. This distance increases to a similar extent and with a time course similar to that of the junctional length as a whole (Fig. 3, closed circles, middle). If the primary mode of growth was at the ends of branches, this distance would not have changed and the pattern of branches would be distorted rather than maintained. Middle: Inset is a camera lucida tracing of the 4 month time point from the junction illustrated in Figure 1. The separation in length between branches ( $a$ increases in parallel with overall junctional length (Fig. 3, open circles, middle). Bottom, Inset is a camera lucida tracing of the 4 month time point from the junction illustrated in Figure 1. The separation in width between branches $(b)$ increases to a similar extent and with a similar time course similar to that of junctional width as a whole (Fig. 3, open circles, bottom). Scale bar (in inset), $20 \mu \mathrm{m}$.

final observation was present in each of the previous views (Fig. 7). In 3 of 99 junctions, new small receptor regions $(<10 \mu \mathrm{m}$ in length) were added to the distribution. In one junction, a small region of receptors was lost from the distribution. Neither the addition or loss of receptor regions had a significant effect on the growth of junctions. Thus, between 2 weeks and 1 year 


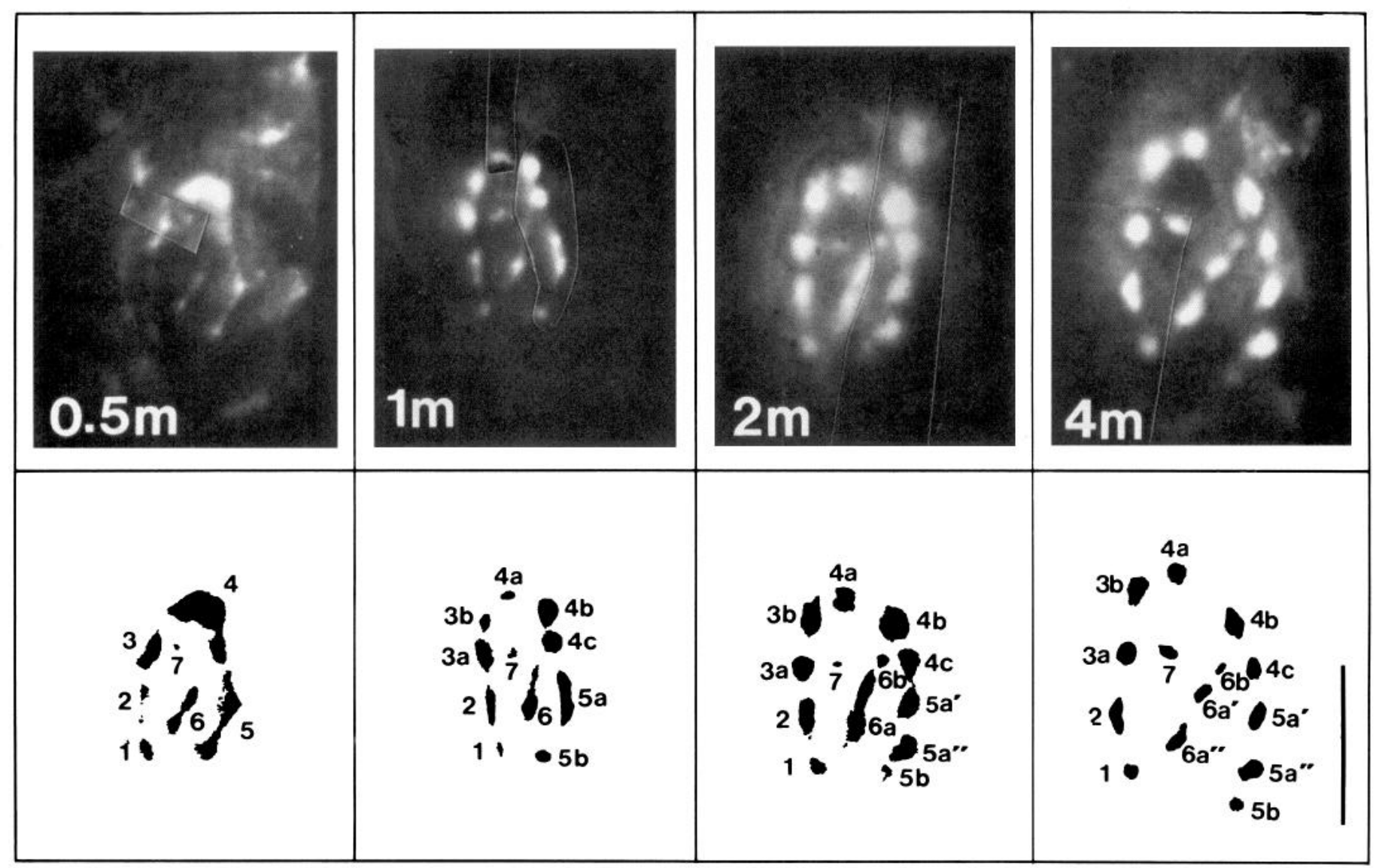

Figure 6. Motor nerve terminal staining changes over time without the addition or loss of branches. Top, 4-Di-2-ASP stained motor nerve terminal arborization viewed on four occasions. Junctional area at 0.5 months, $220 \mu \mathrm{m}^{2}$; at 4 months, $531 \mu \mathrm{m}^{2}$. Bottom: Computer enhancement of 4-Di2-ASP staining. Individual areas of nerve terminal staining are labeled with same number from view to view. Subscripts (a-c) and hash marks (', ") indicate the fission of spots of staining at subsequent views. This fragmentation may represent the addition of new active zones; however, the overall pattern of branches remains unaltered as growth occurs. Scale bar, $20 \mu \mathrm{m}$.

of age, the growth of postsynaptic receptor regions is due to continual enlargement of the existing receptor pattern.

To ask whether motor nerve terminal enlargement induces a secondary expansion of postsynaptic receptor regions or, conversely, whether the enlargement of receptor regions induces outgrowth of motor nerve terminals, we repeatedly viewed the alignment of pre- and postsynaptic elements at growing junctions. In this way, we asked whether pre- or postsynaptic enlargement preceded the other. Both motor nerve terminals and $\mathrm{ACh}$ receptors at the same neuromuscular junctions were followed during the period of most rapid growth (from 0.5 to 3 months; $N=45$; 29 twice; 10 three times; 3 four times; 3 five times). To accurately align the two, motor nerve terminal and ACh receptor images were superimposed using the "bleed through" image of both stains photographed together (see Materials and Methods). At the tips of all branches, as elsewhere in the junctions, these elements remained aligned and their relative sizes remained matched (Fig. 8). Thus, it appears that, at the level of resolution of these techniques, both motor nerve terminals and $\mathrm{ACh}$ receptor regions enlarge in concert without one element discernably leading the other. Moreover, because the predominant form of growth of neuromuscular junctions is not at the ends of branches but is intercalary (see above), it is unlikely that growth occurs in a fashion in which one element could lead the other at the ends of branches.

\section{Growth of neuromuscular junctions parallels growth of muscle} fibers

The enlargement of motor nerve terminals and postsynaptic regions in length and width occurs as the underlying muscle fibers are growing in the same dimensions. By comparing changes in the length and width of neuromuscular junctions to changes in muscle fiber length and width, we hoped to determine whether synaptic growth might be directly related to muscle fiber growth. As mentioned above for individual junctions (Fig. 3), neuromuscular junction length generally increased most rapidly between 2 weeks and 3-4 months of age; after this time, the junctions lengthened more slowly (Fig. 9). The length of the sternomastoid muscle increased to a similar degree and with a similar time course (Fig. 9). Because the muscle's long axis is oriented along the long axis of the mouse, we asked if the noseto-rump length of the mouse increased in extent and with a time course similar to that for junction length and muscle length. As shown in Figure 9, the growth of the muscle in its long axis parallels the overall growth of the mouse in the same axis.

The width of neuromuscular junctions also increased most rapidly from 2 weeks to $3-4$ months of age and then more slowly during the next several months (Fig. 10, top). The diameter of muscle fibers increased to a similar degree and with a similar time course (Fig. 10, bottom). The parallel relationship between 


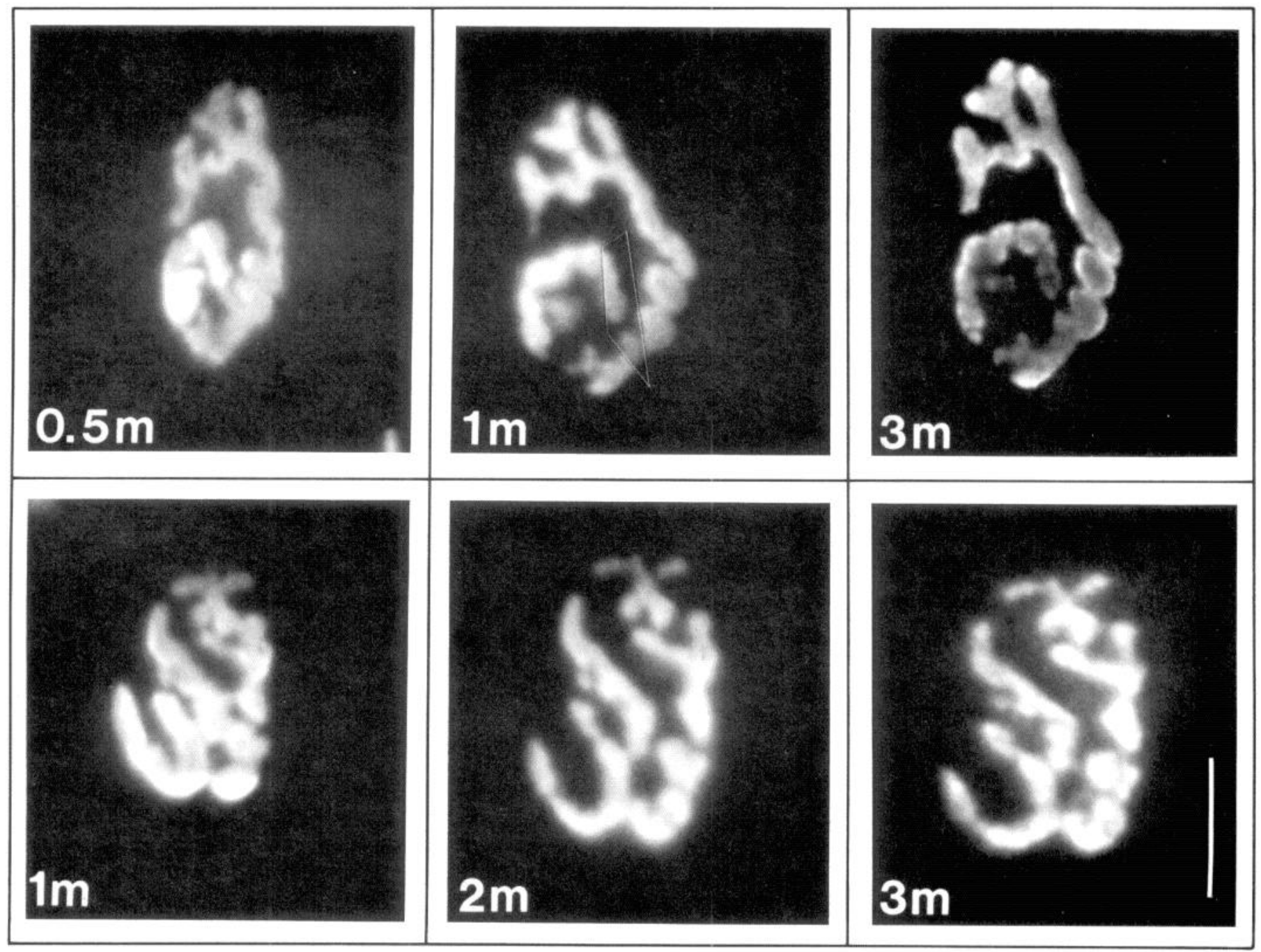

Figure 7. Existing postsynaptic receptor regions enlarge over time. Shown are 2 neuromuscular junctions stained with rhodamine-conjugated $\alpha$-bungarotoxin which were restained and reviewed on 2 subsequent occasions. Existing receptor areas enlarge and the entire distribution expands, without addition or loss of areas. Because all of the receptor images were digitized using automatic gain of the video camera and were subsequently enhanced, the absolute brightness of receptor staining has no quantitative meaning. The regional variations in staining intensity reflect alterations in the plane of focus and curvature of the postsynaptic specializations, and probably do not represent real differences in receptor localization or insertion. Scale bar, $20 \mu \mathrm{m}$.

the increase in length and width of neuromuscular junctions and the length and width of the muscle suggested that growth of neuromuscular junctions might be related to the growth of the underlying muscle fibers.

\section{Postsynaptic ACh receptors spread apart as muscle fibers grow}

In order to determine how receptor regions enlarged without the addition of new branches, we followed existing and newly inserted receptors as muscle fibers grew. By comparing the original receptor distribution labeled with $\alpha$-bungarotoxin with the distribution of the same labeled receptors remaining in the membrane 2 weeks to 1 month later, we observed that the existing receptor molecules come to define a progressively larger postsynaptic area (Fig. 11; see also Fig. 12). When additional $\alpha$-bungarotoxin was added at the subsequent view to label the receptors inserted since the first observation, it was clear that the old labeled receptors occupied the entire enlarged postsynaptic area. This result suggests that receptors spread apart in the muscle fiber membrane as junctions grow.
By following the same labeled receptors between 2 weeks and 1 month of age, we observed some uniformly stained patches of receptors that were redistributed into more clearly discernable separate branches (see, for example, arrows in Fig. 11). The fragmentation of receptor patches is a major aspect of junctional differentiation at earlier ages (Steinbach, 1981; Slater, 1982; Balice-Gordon and Lichtman, 1988). Thus, even in this case where there was an elaboration of branches in the receptor distribution, it did not occur by the "outgrowth" of new receptor areas but rather by the sculpting of branches from an initially more continuously stained region.

To determine the location of new receptors inserted at growing neuromuscular junctions as they enlarged, we initially labeled receptors with rhodamine-conjugated $\alpha$-bungarotoxin (which fluoresces red) in 2-week to 1-month-old animals. Two to 4 weeks later, the original bungarotoxin-labeled receptors were rephotographed. AMCA-conjugated $\alpha$-bungarotoxin (which fluoresces blue) was then applied, to unambiguously label receptors newly inserted at junctions since the first observation $(N=25$ 


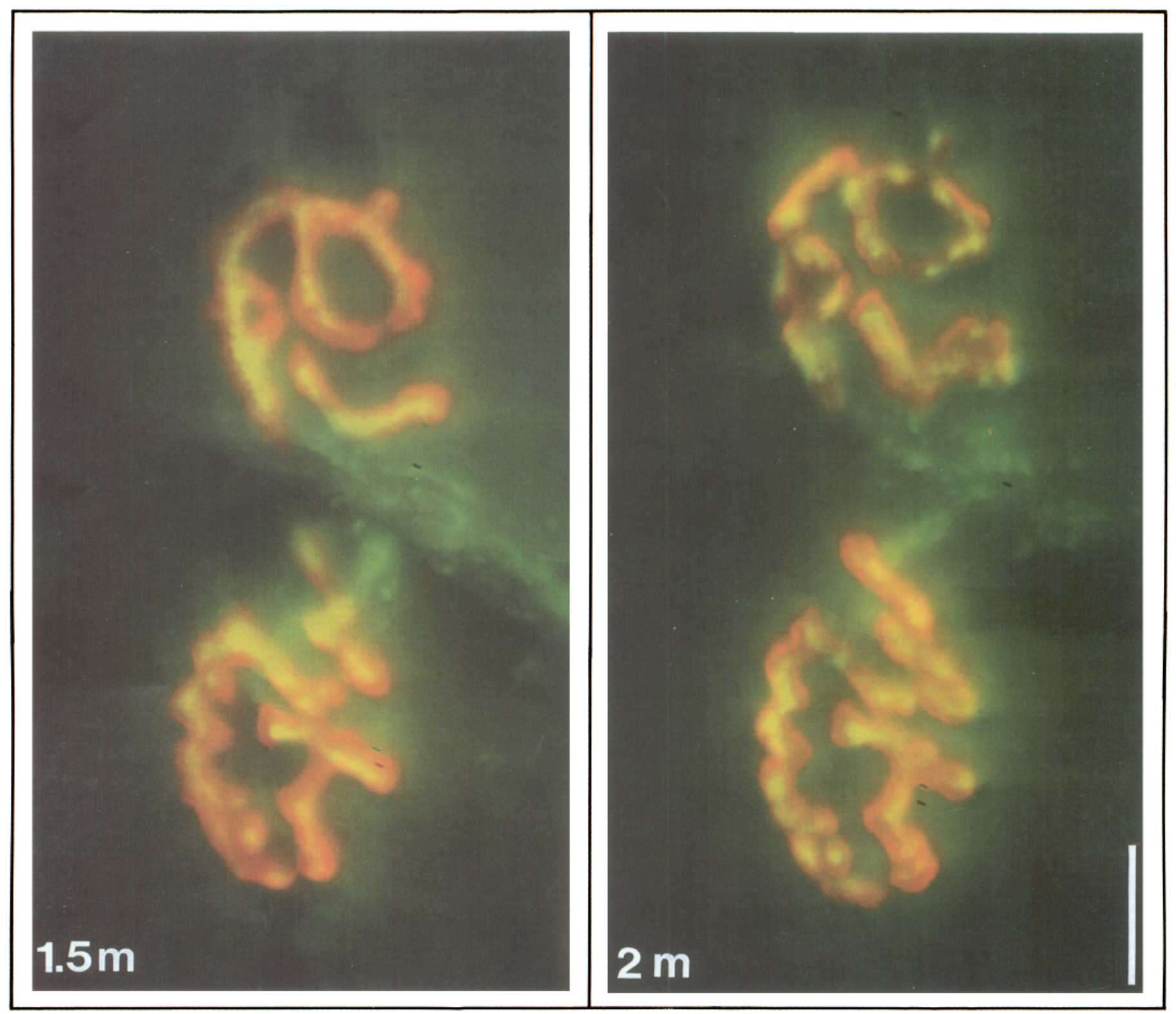

Figure 8. Pre- and postsynaptic elements of neuromuscular junctions remain aligned during growth. 4-Di-2-ASP stained motor nerve terminals (yellow) and rhodamine-conjugated $\alpha$-bungarotoxin stained acetylcholine receptors (red) of the same neuromuscular junction followed over 2 weeks. At the ends of branches as well as elsewhere in the junction, motor nerve terminal staining is matched to the receptor pattern during growth. One of the alterations occasionally observed is the widening of a receptor area with a concomitant addition of spots of 4-Di-2-ASP staining (e.g., end of horizontal branch on right in upper part of junction). Junctional growth, however, occurs independently of this sort of minor alteration. Junction area at 1.5 months, $1409 \mu \mathrm{m}^{2}$, at 2 months, $1686 \mu \mathrm{m}^{2}$. Scale bar, $20 \mu \mathrm{m}$.

junctions). The results of this experiment indicated that new ACh receptors inserted at growing neuromuscular junctions were intercalated uniformly throughout the existing distribution, and not preferentially at the ends of branches or elsewhere within the receptor distribution (Fig. 12). Similar uniform intercalation of new receptors is seen in chick myotubes in vitro (Dubinsky et al., 1989).

In sum, these experiments indicate that postsynaptic specializations expand at the same time, to the same degree, and in the same directions as muscle fibers enlarge. This linkage may mean that the expansion of the postsynaptic specialization is mechanically related to the enlargement of the muscle-like membrane which must accommodate the increasing internal volume of the muscle fiber. Because motor nerve terminals grow in parallel with the expansion of postsynaptic regions, these data also suggest that adherence of nerve terminals to postsynaptic sites might serve as a mechanical explanation for neuromuscular junction growth.

\section{Motor nerve terminals and postsynaptic receptor regions elongate concurrently as muscle fibers are stretched}

To study the relationship between nerve-muscle adhesion and junctional enlargement, we attempted to change the shape of the postsynaptic membrane by stretching sternomastoid muscles in living mice to see if we could induce changes in the shape of motor nerve terminals. Stretching the muscle $(N=5$ muscles; 12 junctions) $10-20 \%$ by pulling it at its ends gave rise to a noticeable lengthening of the ACh receptor sites stained with 


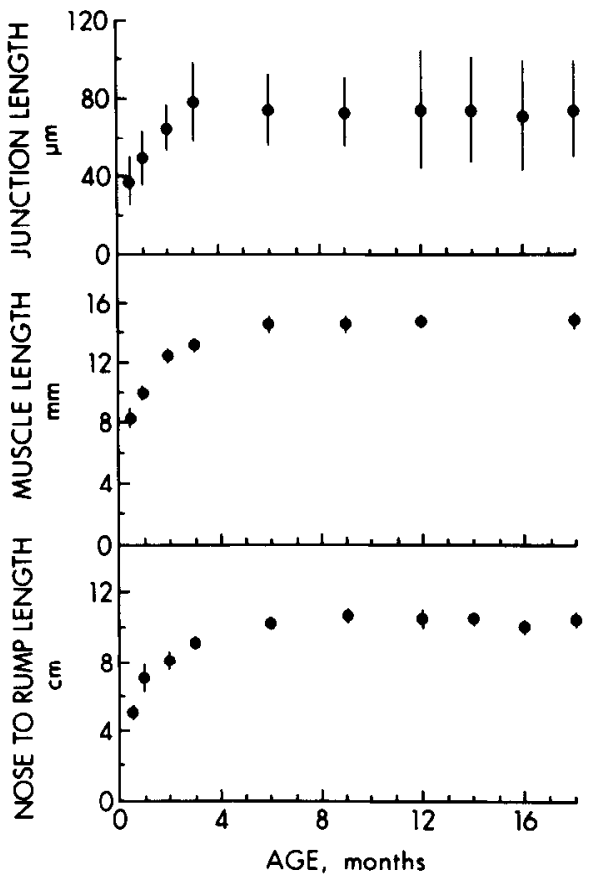

Figure 9. Sternomastoid neuromuscular junctions, muscles, and mice lengthen in parallel. Junctions lengthen rapidly until 3-4 months of age (2.1-fold from 2 weeks to $3-4$ months), and then more slowly; this increase is similar in time course and extent to the rostral-caudal lengthening of the muscle, measured from tendon to tendon (1.8-fold from 0.5 to $3-4$ months), as well as the animal as a whole (1.9-fold from 0.5 to 3-4 months). Points and solid lines represent averages \pm SD of at least 70 junctions, at least 10 muscles and 10 mice measured at each age. No significant differences were noted by sex or strain (Student's $t$ test).

fluorescently tagged $\alpha$-bungarotoxin (Fig. 13, top). When the same junctions were stained with 4-Di-2-ASP, the motor nerve terminals could also be seen to have expanded to the same degree (Fig. 13, bottom). That motor nerve terminals stretch in response to a lengthening of the underlying muscle fiber indicates that the pre- and postsynaptic elements are adherent.

What was perhaps more interesting, however, was that stretching the muscle by pulling it at its ends caused the membrane at neuromuscular junctions, which are located in the middle of the muscle, to stretch. Not only had receptor patches themselves become longer, but the intervening spaces between receptor patches had also expanded. When the muscle was released, the junctions once again assumed their resting shape. Thus, the muscle fiber membrane behaves as if it were elastic and tension exerted at a distance can cause local reversible changes in the membrane. Similarly, the motor nerve terminals arc also apparently clastic, because stretching the muscle fiber causes them to stretch reversibly. This result suggests to us that when muscle fibers elongate during growth, probably by sarcomere addition at their ends (Rowe and Goldspink, 1969), the membrane far from these areas may be mechanically affected, and this may lead to insertion of new membrane constituents which would cause the membrane to grow in the long axis. A similar sequence could underlie the widening of the junction if myofibril addition caused local membrane stretching as well.

\section{Discussion}

Our aim in this work was to study how neuromuscular junctions grow. Our results indicate motor nerve terminal arborizations

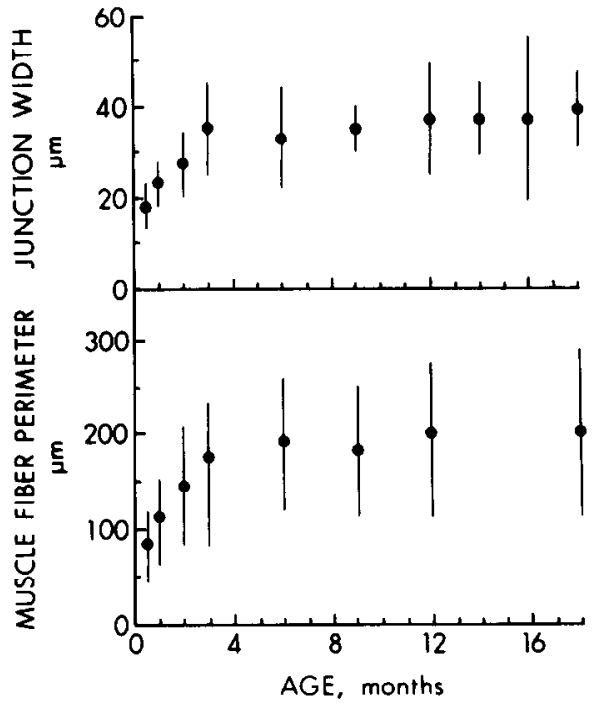

Figure 10. Growth of neuromuscular junctions in width parallels widening of muscle fibers. Junctions increase in width rapidly until 3-4 months of age (2-fold from 0.5 to $3-4$ months) and then more slowly. Muscle fiber perimeter, measured from camera lucida tracings of musclc cross sections, increased with a similar time course and extent (2-fold from 0.5 to $3-4$ months). Points and solid lines represent averages \pm SD of at least 70 junctions measured at each age (same data set as Fig. 9) or at least 100 muscle fibers from each of 5 muscles at each age.

and postsynaptic $\mathrm{ACh}$ receptor distributions increase in length and width similarly to the growth of muscle fibers in these dimensions. By following neuromuscular junctions for long periods, we found that junctions grow by intercalary elongation and expansion of existing motor nerve terminal branches and $\mathrm{ACh}$ receptor areas. There was little evidence of continual remodeling of junctions or addition of new sites of synaptic contact. Pre- and postsynaptic regions remained in alignment as junctions grew. The observation that postsynaptic $\mathrm{ACh}$ receptor areas spread apart as muscle fibers grew suggests that enlargement of postsynaptic sites is due to expansion of the muscle fiber membrane. Thus, structural size matching may be accomplished by the passive expansion of synaptic sites as muscle fibers grow.

\section{Growth of neuromuscular junctions is predominantly intercalary}

In agreement with a large body of published work, we observed that neuromuscular junctions increase in area several fold during the first few months of the animals' lifetime. The correlation between the size of neuromuscular junctions and muscle fibers (see Grinnell and Herrera, 1980; Wernig and Herrera, 1986; Ogata, 1989, for reviews) has been used to argue that there are trophic feedback mechanisms operating that functionally match neuromuscular synapses to their target cells (Nudell and Grinnell, 1983; Slack et al., 1983; Hopkins et al., 1985; Herrera and Werle, 1990). Our data suggest a relatively simple mechanical explanation for this size matching in which the growth of the motor nerve terminals, postsynaptic regions, and the muscle fibers are directly related. Our results argue that there is a causal chain of events, in which terminal enlargement is a physical consequence of its adherence to the postsynaptic region, and postsynaptic enlargement is in turn a direct consequence of the expansion of the postsynaptic membrane surrounding a growing muscle fiber. 


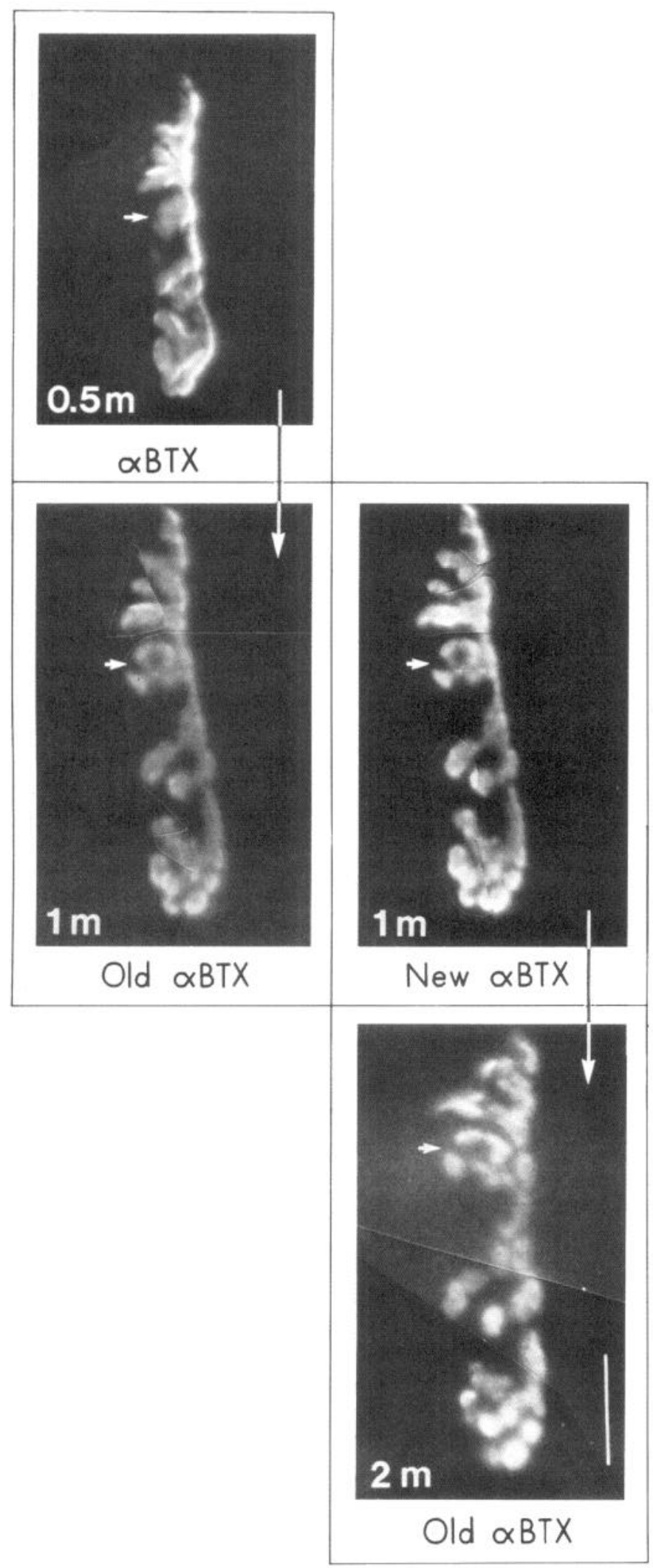

Figure 11. Postsynaptic ACh receptors are redistributed in the plane of the membrane as muscle fibers grow. Acetylcholine receptors were labeled with rhodamine-conjugated $\alpha$-bungarotoxin $(\alpha B T X)$ at the first view and photographed ( 0.5 months of age). Two weeks later, the original $(O l d)$ bungarotoxin-labeled receptors were rephotographed. New bungarotoxin was then applied to label receptors inserted at the junction since the previous view, and the junction photographed again (New).
We believe these results are incompatible with several alternative growth schemes. One alternative is that motor nerve terminal growth induces the expansion of postsynaptic regions. We believe this is untenable in the sternomastoid muscle for several reasons. If motor nerve terminal expansion were instigating postsynaptic expansion (Hill and Robbins, 1988), then nerve terminal growth should occur first, followed by postsynaptic growth. However, we found that pre- and postsynpatic elements remained in alignment at all times as junctions grew. Furthermore, the overall expansion of the nerve terminal arbor precludes the possibility that terminal branches are growing at their ends. It has long been appreciated that growth cone-initiated axonal elongation progressively lengthens the most distal axon branches (Bray, 1970; Landis, 1983). Thus, if nerve terminals initiated their own elongation, one might expect that it would occur by preferentiai growth at the ends of branches. However, we found the distances between internal points of the branching pattern grew as fast as the branches beyond their last bifurcation. It is unclear how a nerve terminal could elongate in this manner independently of the postsynaptic cell. Furthermore, it is hard to imagine how the angle between branch bifurcations would become progressively larger if nerve terminals actively controlled their own growth. The widening of the angle between branches occurs even when branches are not touching each other, thus ruling out crowding as the reason behind the increase in separation between branches.

Our results also are inconsistent with the idea that postsynaptic regions expand first, with the nerve terminal responding by growing into the enlarged synaptic territory. The continued alignment of pre- and postsynaptic areas argues that the 2 are growing synchronously. Furthermore, the receptor regions enlarge by the uniform expansion of existing branches. In order for the motor nerve terminals to actively respond, each existing branch and bifurcation would have to elongate and move in a way exactly matched to the movement of receptor areas as the postsynaptic receptor distribution expanded.

On the other hand, the synchronous expansion of pre- and postsynaptic regions could easily occur if the 2 were in some way attached to each other. There is no question that motor nerve terminals are tightly apposed to postsynaptic regions. In fact, enzymatic or acid treatment is necessary to dislodge motor nerve terminals from muscle fibers (Hall and Kelly, 1971; Desaki and Uehara, 1981). The fact that the 2 stretch in parallel is direct evidence for adhesion (Fig. 13). Because of the large distance involved, it is unlikely that nerve terminals are connected directly to postsynaptic constituents of the muscle fiber membrane. Rather, if nerve terminals and receptor areas are adherent, it is probably by virtue of binding to something in the intervening basal lamina. Thus, if an extracellular substrate for nerve terminal adhesion is itself anchored to the postsynaptic

\footnotetext{
The experiment was repeated one month later. The distribution of the original bungarotoxin-labeled receptors remaining at the subsequent view shows that the original labeled receptors have spread apart, defining a larger postsynaptic area. Individual receptor areas were seen to elongate and widen and the separation between branches also increased. The mature pattern of postsynaptic sites is evident at the first view, albeit smaller and more compact. See legend of Figure 7 for explanation of receptor intensity variations. Arrow indicates an area of receptors that is transformed from a uniform plaque to a series of branches as growth occurs. Area of junction at 0.5 months, $276 \mu \mathrm{m}^{2}$, at 1 month, $703 \mu \mathrm{m}^{2}$, at 2 months, $1165 \mu \mathrm{m}^{2}$; these values are identical for the old and new bungarotoxin labeling. Scale bar, $20 \mu \mathrm{m}$.
} 


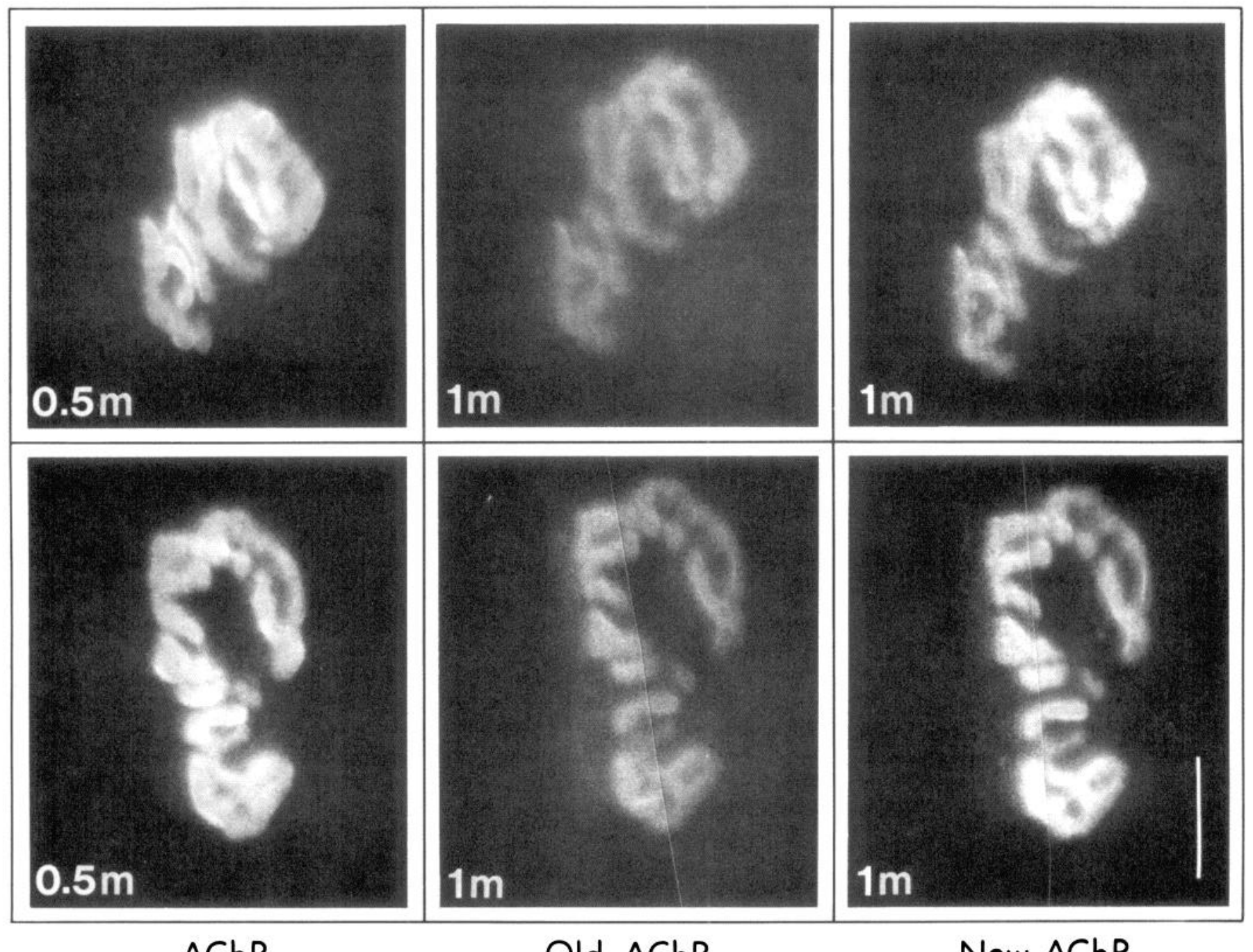

$\mathrm{AChR}$

Old AChR

New AChR

Figure 12. New receptors are intercalated uniformly within growing junctions. Acetylcholine receptors were labeled with rhodamine-conjugated $\alpha$-bungarotoxin at the first view and photographed $(0.5$ months of age). Two weeks later the remaining original (Old $)$ labeled receptors were rephotographed. AMCA-conjugated $\alpha$-bungarotoxin was then applied to label receptors inserted at junctions since the previous observation (New). The new receptors are intercalated uniformly within the enlarged postsynaptic area. Scale bar, $20 \mu \mathrm{m}$.

membrane, then nerve terminals and muscle fibers would be physically attached. In fact, ultrastructural examination of the synaptic cleft at neuromuscular junctions reveals the presence of elements which appear to attach motor nerve terminals to the basal lamina and the basal lamina to postsynaptic receptor regions (Hirokawa and Heuser, 1982). Molecules such as s-laminin located in the basal lamina have been suggested to serve such an adhesive function (Hunter et al., 1989). Adhesion between pre- and postsynaptic elements might ensure that the 2 would grow in parallel. Furthermore, the gradual increase in the angle between motor nerve terminal branches at points of bifurcation can be explained if nerve terminals are being pulled as muscle fibers enlarge.

While adhesion may explain the maintained alignment between nerve terminals and receptor areas it does not explain what causes these elements to enlarge. In order to study this question, we labeled receptors at one time and viewed their location after growth had occurred. We found that receptors gradually spread apart to define a larger postsynaptic area as muscle fibers enlarged. As the receptor pattern enlarged, the spaces between receptor regions also expanded. This overall expansion was analogous to the change in the pattern of an ink drawing on the surface of a balloon being inflated. Whether the expansion seen actually indicates that the muscle fiber membrane is stretching, however, remains unclear. For example, the insertion of new membrane components may push receptors apart. The insertion of new receptors throughout the enlarged synaptic region and intercalation of new membrane components in areas without receptors may thus be either the cause of membrane expansion or the consequence of membrane stretching. In either case, the growth of neuromuscular synapses is very likely to be a direct consequence of muscle fiber growth. Similarly the stretched nerve terminal may respond by intercalating additional membrane and also adding new intracellular constituents such as active zones.

Muscle fibers grow in 2 ways: entirely new myofibrils are added and in existing myofibrils new sarcomeres are added probably at the ends (Rowe and Goldspink, 1969). Myofibril 
Figure 13. Stretching of muscle fibers by pulling them at their ends results in elongation of pre- and postsynaptic elements of neuromuscular junctions. Portion of a junction stained with AMCA conjugated $\alpha$-bungarotoxin (top) and 4-Di-2-ASP (bottom) in a 3-monthold mouse. During stretching, the length of the longest receptor branch increased from 35 to $39 \mu \mathrm{m}$; this increase was precisely matched by motor nerve terminal elongation. The spacing of sarcomeres also increased but was variable from experiment to experiment. Scale bar, $20 \mu \mathrm{m}$.

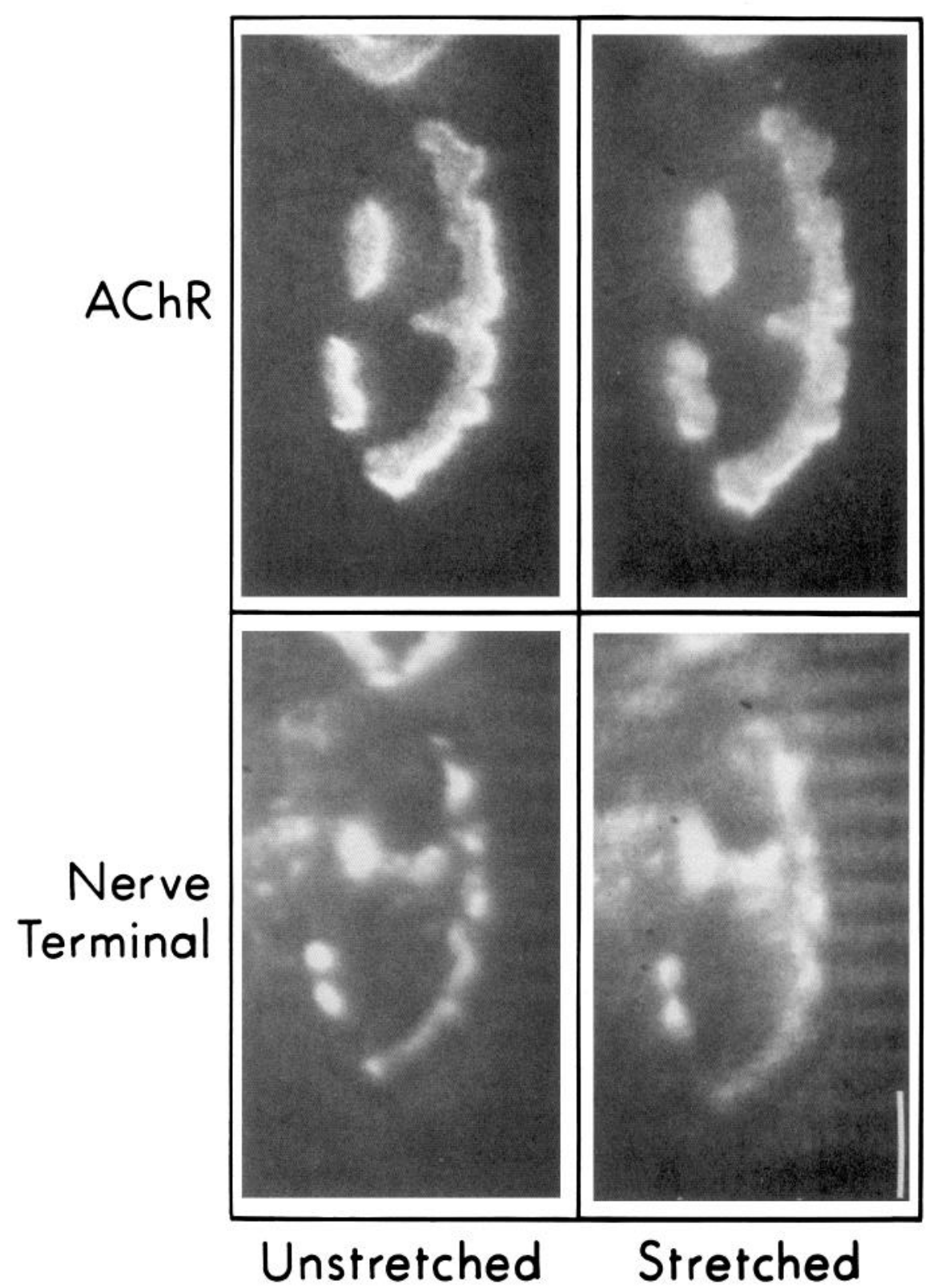

addition gives rise to increased muscle fiber diameter, whereas new sarcomeres added at the ends of existing myofibrils give rise to increased muscle fiber length. Because these internal constituents of muscle fibers are growing, the muscle fiber membrane must enlarge as well. This can be appreciated by the progressive increase in the number of sarcomeres that underlie junctions as they grow (Figs. 1, 4). That we can simulate (temporarily) growth by stretching a muscle acutely may mean that membrane stretching is the impetus for membrane growth. In fact, stretching is thought to be the stimulus for muscle fiber enlargement because stretched fibers add new sarcomeres (Williams and Goldspink, 1973). Stretching may also initiate the insertion of new components into the growing membrane. Whatever mechanism links muscle fiber membrane expansion to the growth of internal constituents, it is likely that one of its consequences is the proportional expansion of the neuromuscular junction.
These results are different from those obtained in frog, where motor nerve terminals appear to preferentially elongate at the ends of distal branches (Herrera et al., 1989). These results are also in contrast to conclusions derived from another fast twitch mammalian muscle, where motor nerve terminals are thought to grow preferentially at their ends, followed by receptor accumulation under the new terminal sprouts (Hill and Robbins, 1988; Robbins, 1988). Our results also differ from those obtained in a slow-twitch mammalian muscle where substantial loss of pre- and postsynaptic regions was observed over time (Wigston, 1989). Given these other results, our finding that neuromuscular junctions grow by overall expansion of existing regions should not be taken to exclude additional mechanisms which may change neuromuscular synapses over time. Nonetheless, our results show that remodeling by the addition or retraction of synaptic sites is not necessary for and is unrelated to the ongoing growth of neuromuscular junctions. Thus, the 
present results (see also Lichtman et al., 1987) do not support the popular "replacement hypothesis" first promulgated by Barker and Ip (1966) that nerve terminals are in a state of continual renewal in which the forces of sprouting and degeneration are in dynamic equilibrium. These workers were the first to suggest that continual "sprouting effects the replacement of old endplates which degenerate after a limited life span." In the sternomastoid muscle, existing synaptic sites are not continually replaced with new ones in animals between 2 weeks and at least 1 year of age.

Despite the absence of remodeling, 4-Di-2-ASP staining of motor nerve terminals did change over time. This alteration in staining appears as a progressive fragmentation of stained areas into a series of spots (Fig. 6). Because 4-Di-2-ASP stains an intracellular compartment of nerve terminals, probably where mitochondria are (Lichtman et al., 1989), this altered staining pattern might imply that the intracellular organization of the nerve terminal is changing. Mitochondria are known to be concentrated at release sites for neurotransmitters (see Wernig and Herrera, 1986, for review). Because large nerve terminals can release more neurotransmitter than smaller nerve terminals, this change in the distribution of mitochondria may be related to a change in the organization and number of neurotransmitter release sites in growing terminals. Indeed, as junctions enlarge, there are progressively more spots of 4-Di-2-ASP staining (see Fig. 6). This observation also serves as a caveat in the interpretation of synaptic morphology based solely on the distribution of intracellular markers. It is only by repeatedly observing the same structures many times and having an additional reliable marker for postsynaptic sites ( $\alpha$-bungarotoxin) that we could interpret 4-Di-2-ASP staining of presynaptic motor nerve terminal morphology. Alternative staining approaches which vitally label motor nerve terminal and axon membranes may prove useful (see, for example, Balice-Gordon and Lichtman, 1989).

In summary, we conclude that the "size matching" observed between neuromuscular junctions and muscle fibers is related to the mechanical enlargement of neuromuscular synapses as postsynaptic muscle fibers grow. If motor nerve terminals intercalate new active zones throughout their enlarged arborization, then structural size matching would have a functional correlate. The stability of both pre- and postsynaptic elements of neuromuscular junctions, as well as their precise alignment during growth, are consistent with adhesion between motor nerve terminals and receptor sites perhaps involving an interaction with the intervening synaptic basal lamina (see Sanes, 1989, for recent review). This adhesivity may be the basis for the stable maintenance of neuromuscular junctions for long periods of the animals' lifetime. Adhesivity between pre- and postsynaptic elements of neuromuscular synapses may be altered in very young, very old, degenerating and reinnervated muscles, where remodeling of both motor nerve terminals and $\mathrm{ACh}$ receptor areas is routinely observed (Balice-Gordon and Lichtman, 1988, and unpublished observations; Rich and Lichtman, 1989a, b). If similar adhesivity exists between pre- and postsynaptic elements of synapses in the CNS, then as neuronal cell bodies or dendrites grow, existing synaptic sites may be pulled along and remain anatomically and functionally intact during growth.

\section{References}

Balice-Gordon, R. J., and J. W. Lichtman (1988) Elimination and elaboration of pre- and postsynaptic sites during synaptic competition at developing neuromuscular junctions. Soc. Neurosci. Abstr. 14:894.

Balice-Gordon, R. J., and J. W. Lichtman (1989) Competing motor nerve terminals and the acetylcholine receptors underlying them are rearranged during synaptic elimination. Soc. Neurosci. Abstr. 15: 165.

Barker, D., and M. C. Ip (1966) Sprouting and degeneration of mammalian motor axons in normal and de-afferentated skeletal muscle. Proc. Natl. Acad. Sci. USA 163: 538-554.

Bennett, M., and J. Raftos (1977) The formation and regression of synapses during the re-innervation of axolotl striated muscles. J. Physiol. (Lond.) 265: 261-295.

Bray, D. (1970) Surface movements during the growth of single explanted neurons. Proc. Natl. Acad. Sci. USA 65: 905-910.

Brown, M., R. Holland, and W. Hopkins (1981) Motor nerve sprouting. Annu. Rev. Neurosci. 4: 17-42.

Desaki, J., and J. Uehara (1981) The overall morphology of neuromuscular junctions as revealed by scanning electron microscopy. J. Neurocytol. 10: 101-110.

Dubinsky, J. M., D. J. Loftus, G. D. Fischbach, and E. L. Elson (1989) Formation of acetylcholine receptor clusters in chick myotubes: Migration or new insertion? J. Cell Biol. 109: 1733-1743.

Grinell, A. D., and A. A. Herrera (1980) Physiological regulation of synaptic effectiveness at frog neuromuscular junctions. J. Physiol. (Lond.) 307: 301-317.

Hall, Z. W., and R. B. Kelly (1971) Enzymatic detachment of endplate acetylcholinesterase from muscle. Nature [New Biol.] 232: 62-63.

Harris, J. B., and R. R. Ribchester (1979) The relationship between end-plate size and transmitter release in normal and dystrophic muscles of the mouse. J. Physiol. (Lond.) 296: 245-265.

Herrera, A. A., and M. J. Werle (1990) Mechanisms of elimination, remodelling and competition at frog neuromuscular junctions. J. Neurobiol. 21: 73-98.

Herrera, A. A., L. R. Banner, and N. Nagaya (1988) Discrepancies between histological and in vivo observations of motor nerve terminal remodelling. Soc. Neurosci. Abstr. 14: 1209.

Herrera, A. A., L. R. Banner, and N. Nagaya (1990) Repeated, in vivo observation of frog neuromuscular junctions: Remodelling involves concurrent growth and retraction. J. Neurocytol. (in press).

Hill, R., and N. Robbins (1988) Dynamic structural rearrangements at the growing and adult mouse neuromuscular junction. Soc. Neurosci. Abstr. 14: 1208.

Hirokawa, N., and J. E. Heuser (1982) Internal and external differentiations of the postsynaptic membrane at the neuromuscular junction. J. Neurocytol. 11: 487-510.

Hopkins, W. G., M. C. Brown, and R. J. Keynes (1985) Postnatal growth of motor nerve terminals in muscles of the mouse. J. Neurocytol. 14: 525-540.

IIunter, D. D., V. Shah, J. P. Merlie, and J. R. Sanes (1989) A lamininlike adhesive protein concentrated in the synaptic cleft of the neuromuscular junction. Nature 338: 229-234.

Kelly, S. S. (1978) The effect of age on neuromuscular transmission. J. Physiol. (Lond.) 274: 51-62.

Khalfan, H., R. Abuknestra, M. Rand-Weaver, R. G. Price, and D. Robinson (1986) Aminomethyl coumarin acetic acid: a new fluorescent labelling agent for proteins. Histochem. 18: 497-499.

Kuno, M., S. A. Turkanis, and J. N. Weakly (1971) Correlation between nerve terminal size and transmitter release at the neuromuscular junction of the frog. J. Physiol. (Lond.) 213: 545-556.

Landis, S. C. (1983) Neuronal growth cones. Annu. Rev. Physiol. 45: $567-580$.

Lichtman, J. W., L. Magrassi, and D. Purves (1987) Visualization of neuromuscular junctions over periods of several months in living mice. J. Neurosci. 7: 1215-1222.

Lichtman, J. W., W. Sunderland, and R. S. Wilkinson (1989) High resolution imaging of synaptic structure using a simple confocal microscope. New Biologist 1: 75-82.

Magrassi, L., D. Purves, and J. W. Lichtman (1987) Fluorescent probes that stain living nerve terminals. J. Neurosci. 7: 1207-1214.

Nudell, B. M., and A. D. Grinnell (1983) Regulation of synaptic position, size and strength in anuran skeletal muscle. J. Neurosci. 3: 161-176.

Nyström, B. (1968) Postnatal development of motor nerve terminals in "slow-red" and "fast-white" cat muscles. Acta Neurol. Scand. 44: 363-383.

Ogata, T. (1989) Structure of motor endplates in the different fiber types of vertebrate skeletal muscles. Arch Histol. Cytol. 51: 385-424. 
Ravdin, P., and D. Axelrod (1977) Fluorescent tetramethyl rhodamine derivatives of a-bungarotoxin: Preparation, separation, and characterization. Anal. Biochem. 80: 585-592.

Rich, M. M., and J. W. Lichtman (1989a) In vivo visualization of pre- and post-synaptic changes during synapse elimination in reinnervated mouse muscle. J. Neurosci. 9: 1781-1805.

Rich, M. M., and J. W. Lichtman (1989b) Motor nerve terminal loss from degenerating muscle fibers. Neuron 3: 677-688.

Robbins, N. (1988) Plasticity at motor nerve terminals. In NerveTarget Cell Trophic Communication, H. Fernandez, ed., pp. 199215, CRC Press, Boca Raton.

Rowe, R. W. D., and G. Goldspink (1969) Muscle fibre growth in five different muscles in both sexes of mice. J. Anat. 104: 519-530.

Sanes, J. R. (1989) Extracellular matrix molecules that influence neural development. Annu. Rev. Neurosci. 12: 491-516.

Slack, J. R., S. Pockett, and B. A. E. MacClement (1983) Regulation of postnatal growth of motor end plates in rat soleus muscle. Exp. Neurol. 80: 321-328.

Slater, C. R. (1982) Postnatal maturation of nerve-muscle junctions in hindlimb muscles of the mouse. Dev. Biol. 94: 11-22.

Steinbach, J. (1981) Developmental changes in acetylcholine receptor aggregates at rat skeletal neuromuscular junctions. Dev. Biol. 84:267276.

Teräväinen, H. (1968) Development of the myoneural junction in the rat. Z. Zellforsch. 87: 249-265.

Wernig, A., and A. A. Herrera (1986) Sprouting and remodelling at the nerve-muscle junction. Prog. Neurobiol. 27: 251-291.

Wigston, D. J. (1989) Remodeling of neuromuscular junction in adult mouse soleus. J. Neurosci. 9: 639-647.

Williams, P. E., and G. Goldspink (1973) The effect of immobilization on the longitudinal growth of striated muscle fibers. J. Anat. 116:4555. 